\title{
Teaching through Learning Analytics: Predicting Student Learning Profiles in a Physics Course at a Higher Education Institution
}

\author{
Elvira G. Rincon-Flores ${ }^{1,2,5}$, Eunice Lopez-Camacho³, Juanjo Mena ${ }^{4}$, Omar Olmos ${ }^{5 *}$ \\ ${ }^{1}$ Institute for the Future of Education, Tecnologico de Monterrey (Mexico) \\ ${ }^{2}$ School of Humanities and Education, Tecnologico de Monterrey, GRIAL research group, Universidad de Salamanca (Spain) \\ ${ }^{3}$ Independent Researcher (United States) \\ ${ }^{4}$ Education Department, Salamanca University, Institute of Psychology and Educations Kazan Federal \\ University (Russia) \\ ${ }^{5}$ School of Engineering and Science, Tecnologico de Monterrey (Mexico) \\ Received 24 November 2020 | Accepted 16 October 2021 | Published 25 January 2022

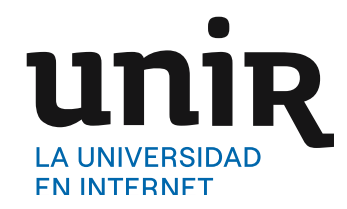

\section{ABSTRACT}

Learning Analytics (LA) is increasingly used in Education to set prediction models from artificial intelligence to determine learning profiles. This study aims to determining to what extent K-nearest neighbor and random forest algorithms could become a useful tool for improving the teaching-learning process and reducing academic failure in two Physics courses at the Technological Institute of Monterrey, México $(n=268)$. A quasiexperimental and mixed method approach was conducted. The main results showed significant differences between the first and second term evaluations in the two groups. One of the main findings of the study is that the predictions were not very accurate for each student in the first term evaluation. However, the predictions became more accurate as the algorithm was fed with larger datasets from the second term evaluation. This result indicates how predictive algorithms based on decision trees, can offer a close approximation to the academic performance that will occur in the class, and this information could be use along with the personal impressions coming from the teacher.

\section{KEYWORDS}

Adaptive Learning, Educational Innovation, Higher Education, Learning Analytics, Predictive Algorithms.

OI: $10.9781 /$ ijimai.2022.01.005

\section{INTRODUCTION}

EARNING Analytics (LA) is understood as statistical work and
computer science applied to educational environments to enhance
learning. Educational processes generate much data that can be used
to generate actionable insights to innovate the way students learn.
LA represents a huge opportunity in higher education for teachers,
researchers, and education officials [1]. However, it is not hard to find
many educational institutions that have a vast amount of data, but it
is not utilized to improve educational processes [2] and [3]. A major
limitation is a fact that the data is generated after the courses are
completed [4], too late to provide timely feedback to the student and to
offer adaptative measures to improve their learning. Also, researchers
like Vieira, Parsons \& Byrd [5], \& Wong [6] claim that currently
there is not yet a knowledge field that combines effectively LA and
educational theory. In addition, most of what has been developed in
this direction are related to online education [7] and [8] and cannot be
applied to face-to-face instruction.

The damage caused by the COVID-19 pandemic has spread to

${ }^{*}$ Corresponding author.

E-mail address: oolmos@tec.mx most of the countries of the world, not only in the field of health and economics but also to education [9]. While some educational institutions decided to stop their academic activities, others decided to continue online. This represented a significant change for both teachers and students, which has led to rethinking the teachinglearning process [10]. These changes have also affected students emotionally and have urged educational institutions to design strategies to minimize the damage. The Association for Psychological Sciences [11] summarized mental health impacts in children and adults: increased stress levels due to isolation (with consequences on mental and physical health), and anxiety and depression due to overflow of information. This problem takes on various nuances in a world in which inequality prevails. While some educational institutions have the resources to offer online educational environments, others do not have an adequate technological infrastructure to deal with confinement, or rather than following a traditional system schools do not have innovative methodologies to optimally cope with the effects of the pandemic [9] and [10]. Thus, taking as a starting point the ecosystems of educational institutions that have the resources to continue with classes online, it is important to promote motivation to reduce frustration, promote autonomy, flexibility, and frequently give positive feedback [12]. Likewise, it could be valuable for both teachers and students to have a predictive algorithm that allows the teacher 
to have a general forecast about the performance of the group and thus redouble efforts in those cases with grim predictions. Similarly, the student could have the option of knowing their forecast to better manage their academic period.

Olmos et al. [13] developed an Artificial Intelligence (AI) algorithm based on classification algorithms to forecast the students' academic performance in a Physics engineering course. The forecasting model uses the algorithms K-nearest neighbor and random forest at its core. $\mathrm{K}$-nearest neighbor is a non-parametric algorithm that works by grouping data in similar sets for continuous or categorical prediction [14]. On the other hand, the random forest algorithm uses a group of decision trees, each of them initiated randomly and independently [15]. To begin the process of predicting academic performance, both algorithms are trained with data from a similar sample of students. In 2016, the model training was initially carried out using biometric information such as neuronal frequencies, facial recognition, heart rate, as well as student academic information [13]. Then, to make the predictions of the target group, the algorithm received the students' some set of grades of each of the various activities from the first evaluation period, one by one, making a new prediction with the grades of each activity. In the fourth run, the photographs of each student were used for facial geometric recognition and the final prediction was obtained. In Fig. 1 it can be seen how the predictive algorithm acquires more precision as more data it receives more input.

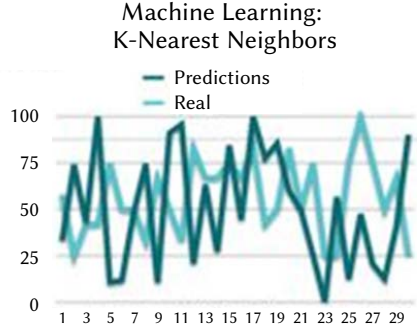

(a)

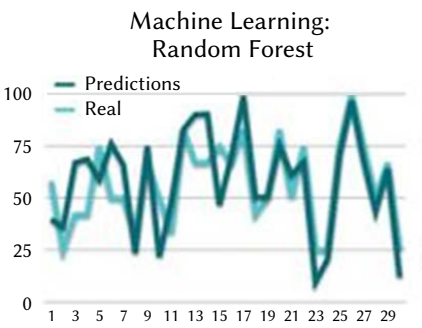

(c)

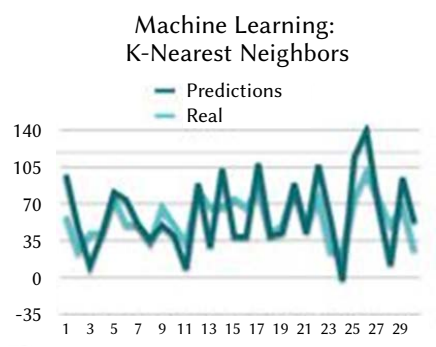

(b)

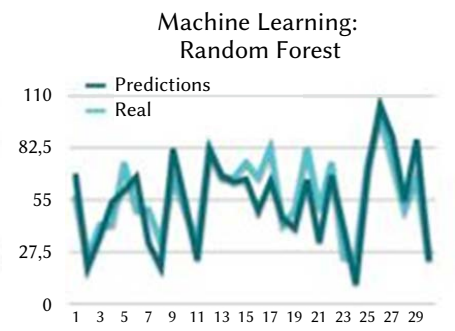

(d)
Fig. 1. Algorithm training with a) Quizzes. b) Quizzes + Homework (HW). c) Quizzes + HW + Students surveys to evaluate teachers (ECOA). d) Quizzes + $\mathrm{HW}+\mathrm{ECOA}+$ Biometrics.

Based on these promising results, we decided to replicate the study with two Physics courses: Physics I (two groups) and Physics II (three groups). These five groups had different instructors. The course consists of three evaluation periods. This study focuses on the first two terms evaluations. The main objective is to determine to what extent the algorithm could become a useful tool for improving the teaching-learning process and reducing academic failure through the timely implementation of preventive adaptive measures.

This research work first presents a theoretical framework that addresses concepts around the artificial intelligence algorithms used. The importance of testing learning models in education based on predictive algorithms serves as a reference in the application of adaptive learning paths in face-to-face learning environments. Then, the methodology is explained and finally, the most relevant results are presented.
II. Theoretical Framework

In the last five years, the use of prediction models that use artificial intelligence to determine profiles has increased dramatically. Companies such as Netflix, Facebook, and Amazon, are examples of this [16] and [17]. This technological development has also been recently spreading to the educational field. The first focuses on the result of student performance, searching through data and automated mechanisms in intelligent Machine Learning algorithms, to draw a line of action that allows the student to strengthen their deficiencies and gradually achieve their performance objectives [18], such as the ALEKS platform, online tutoring, and assessment program, to supplement math instruction [19]. The second way is related to the adaptation of the instructor's actions, intending to generate the actions necessary to adapt to the student's profile and thereby achieve an improvement in their learning [20] and [21]. Adaptive Learning is possible and has become a field of research, particularly in contexts where a vast amount of data can be gathered, and variables can be more controlled. This is the case of Massive, Open, and Online Courses (MOOCs), other online courses, tutorials, computer games, among others [20]. Adaptive Learning has also been tried in hybrid models or Blend Learning. López, Muniesa, and Gimeno [22] designed an adaptive experience on the Moodle platform, in which users were guided through the instructional design activities, adapting at their own pace, the results were positive.

Learning Analytics aims to collect data, analyze it, and generate insights about the students and their contexts to improve their learning, as well as the learning environment [23]. Thanks to advances in the field of computing, interesting opportunities have been created to collect and analyze big datasets [5]. Many algorithms can be applied to the data to discover patterns and make predictions. Random forest is an example of such algorithms [24]. Random Forest uses a combination of predictive variables and a group of decision trees. Each tree provides a prediction based on a random sample of data. The most common prediction becomes the final prediction of the model [15], [25]. Thus, with the help of artificial intelligence, specifically, the use of random decision tree algorithms, it is possible to analyze and identify patterns in populations with a large number of variables [26]. Another algorithm is the K-Near Neighbors which has the purpose of agglutinating the information in similar groups [14].

The combination of algorithms is an innovative model in educational processes since it is presented as a combination of statistical, probabilistic, and forecasting models, in addition to being affordable for most educational institutions.

\section{MEthoDS}

\section{A. Methods}

This study is a result of a research project entitled: "Adaptive based on predictive" carried out at the Tecnologico de Monterrey (Mexico) in a Physics course for undergraduate students. The research embraces a mixed and quasi-experimental methodological approach [27] and [28] with an emphasis on the quantitative data (QUANàqual) to validate and complement the quantitative findings.

A questionnaire of fourteen Likert-type items was handed out to participants. Responses were ranked from 0 (completely disagree) to 5 (completely agree). The research study followed four phases [29]: a.Questionnaire design and validation, b.application and uploading of the online questionnaire, c. statistical data analysis, and d. final report and improvement proposals. 


\section{Materials}

The materials used were the inputs that were used to train the algorithms and to conduct the forecasts. They consisted of teachers' notes, students' photographs, academic records, and the teachers' grades of two terms evaluation.

\section{Participants}

The sample consisted of 268 graduate students enrolled in Physics I and Physics II courses in engineering. Each course was divided into control and experimental groups. Five instructors (teachers) delivered the instructional content.

\section{Tasks and Methods}

Initially, the algorithms were trained with the graduate students' grades and self-photographs from previous editions of the Physics I and Physics II courses. In a second phase, the predictions of grades for the first evaluation period were calculated for the experimental groups, using the photographs of the students as the only input. Photography as input was used to recognize facial features so that the algorithm could generate an association matrix, when there is not enough academic information on students $\mathrm{n}<5$ activities. The information generated from the identification image of each student is used as a reference mark, associating the semantic vector extraction property of the image [13]. At this very moment, the forecasts were released to each teacher so that they applied adaptive measures based on these grades' predictions. The teachers communicated these adaptive measures to the research team through interviews. In a third phase, after the end of the first evaluation period, three forecasts were recalculated for each group, one using only the photography as input, another using photography and the first evaluation period grade, and the third, using only the first evaluation period grade. As the last phase, interviews were done with the students at the end of the course to know their perception of the possibility of knowing the prediction of their grades.

The algorithms used to calculate the forecasts of the first-period grades were K-Nearest Neighbors and Random-Forest. Only the Random-Forest was used to forecast the second evaluation period since it was the one that gave the best result the first time.

To evaluate the precision of the forecasts, 2 error measures were used, and a very elementary reference forecast was constructed for comparison purposes. The error measures used were: Mean Absolute Deviation (MAD) and Average Absolute Percentage Error (MAPE). Equations (1) and (2) show how these measurements are calculated.

$$
\begin{aligned}
& \left(\frac{1}{n}\right) \sum \mid \text { Actual }- \text { Forecast } \mid \\
& 100 *\left(\frac{1}{n}\right) \sum \frac{\mid \text { Actual-Forecast } \mid}{\text { Actual }}
\end{aligned}
$$

where $n$ is the number of data entries.

The second partial grades were collected from both the control and experimental groups to determine the extent of the adaptive routes in the control groups. Averages are compared with the parametric hypothesis test using the Student's $t$-statistic.

It is important to mention that, at the beginning of the data collection process, the students signed a letter in which they agreed that their academic photographs be used for this research.

\section{RESUlts}

\section{A. Results}

The results of the forecasts of the five instructors for the first and second evaluation periods are shown in Fig. 2.

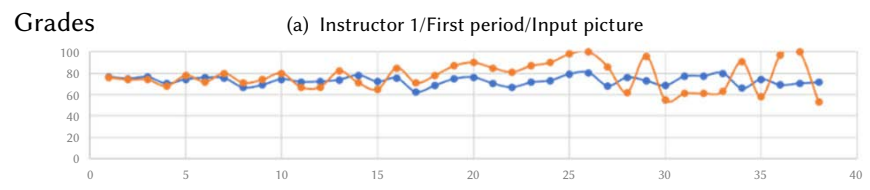

(a) Instructor $1 /$ Second period/Input picture and first period scores

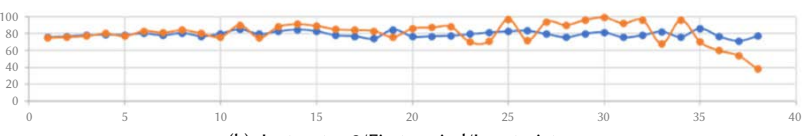

(b) Instructor 2/First period/Input picture

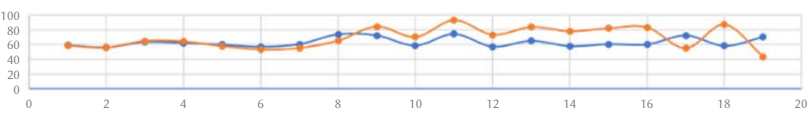

(b) Instructor 2/Second period/Input first period scores

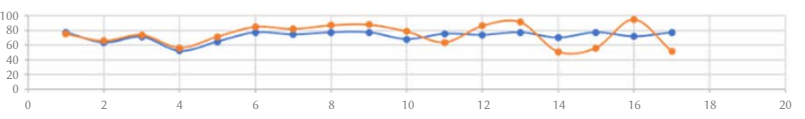

(c) Instructor 3/First period/Input picture

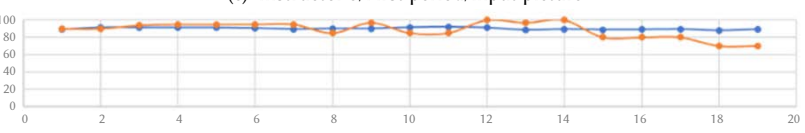

(c) Instructor $3 /$ Second period/Input picture and first period scores

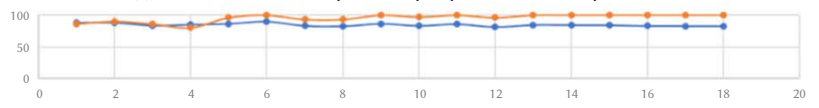

(d) Instructor 4/First period/Input picture

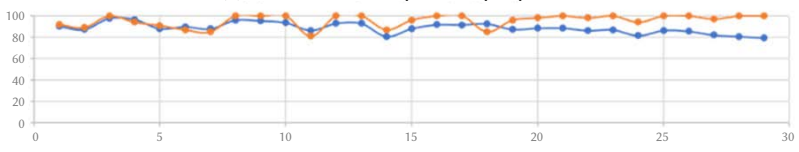

(d) Instructor 4/Second period/Input first period scores

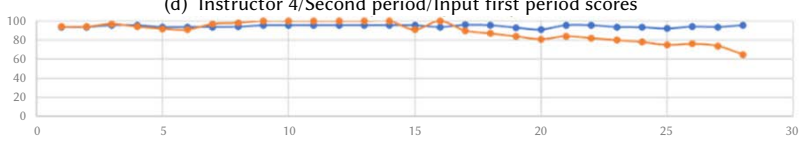

(e) Instructor 5/First period/Input picture

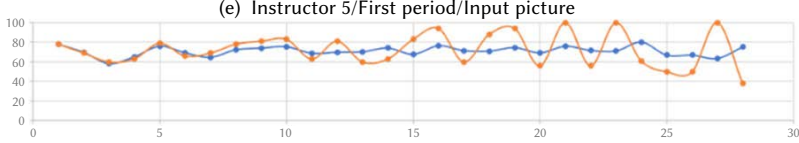

(e) Instructor 5/Second period/Input first period scores

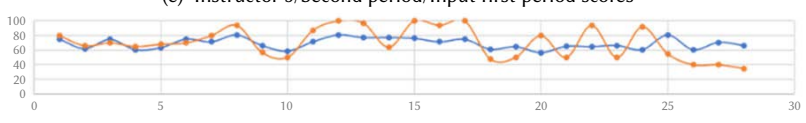

Students

Fig. 2. Predictive and real results of the first and second evaluation period. The Physics I instructors are 1 and 2, the rest are from Physics II (blue= forecasted student performance, orange=actual performance).

Fig. 3 shows the set of adaptative measures implemented by each instructor once they knew the first forecasts for their groups. Each instructor chose what kind of intervention to do for those students with a failing grade forecast. The idea was to prevent the forecast to happen in those cases.

In a second stage, three predictions were calculated for the second evaluation term: one using only photography as input, another using photography and grades from the first evaluation period, and a third using only the grades. Then the best of the three forecasts was selected for each teacher. For instructors 1 and 3 the best forecasts were first period grades and photographs; while for Instructors 2, 4, and 5, the best forecast was generated using only the first-period grades. See Fig. 4. As it might have been expected, grades from the first evaluation period were a good predictor for the second-period grades. 


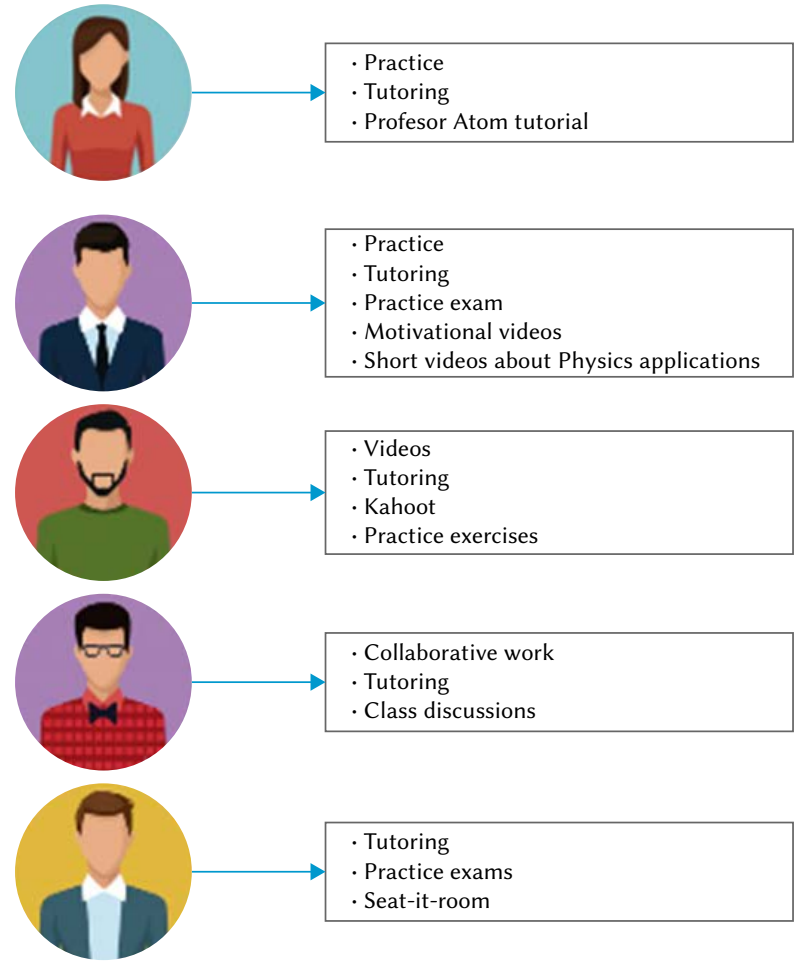

Fig. 3. Summary of interviews with instructors. The Physics I instructors are the first two, the rest are from Physics II.

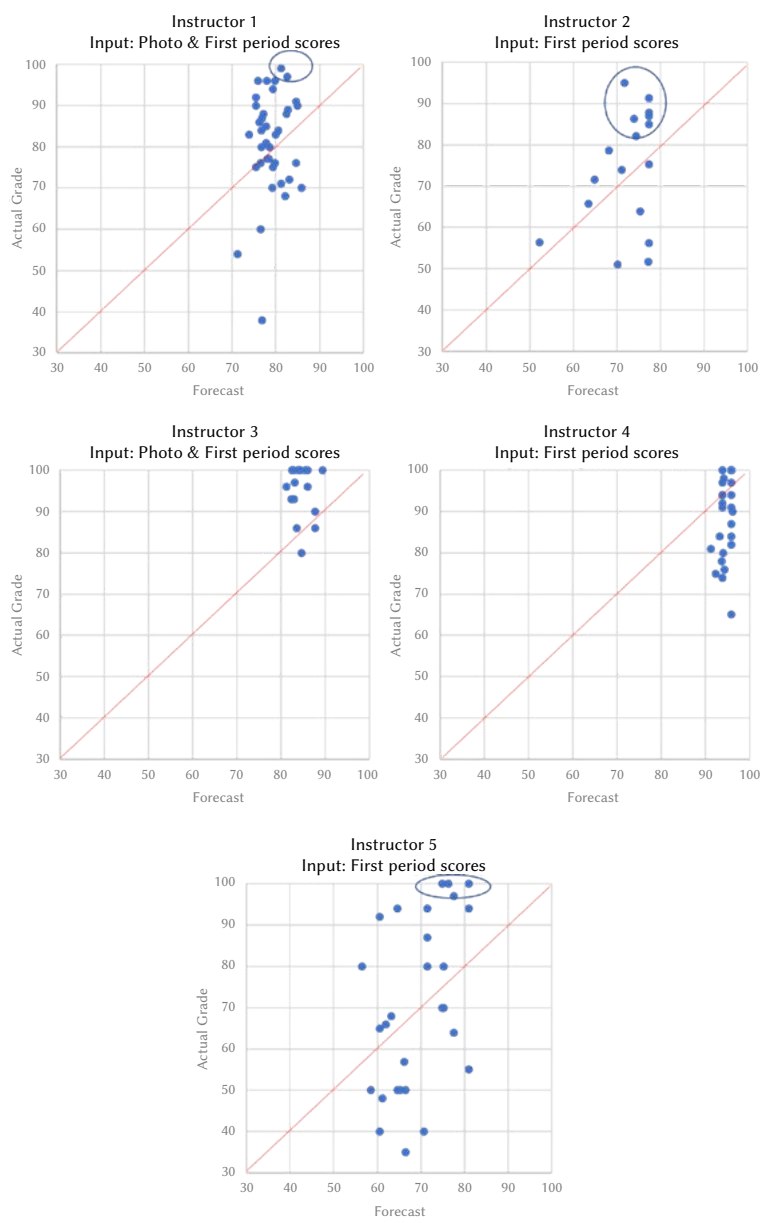

Fig. 4. Predictive and actual students' performance from the second term evaluation using different inputs (Experimental groups). Note that the highest grades in 3 of the groups correspond to some of the highest predictions.
Comparing the first and second term forecasts, the gap observed in the second one is smaller, particularly in the results obtained from instructors 2, 3, and 4. It can be noted that the forecasts generated by the model have a smaller standard deviation than the actual grades because grades vary based on many factors.

To validate the quality of the forecasts generated by the algorithm, a reference forecast was built as a basis for comparison [30]. A reference forecast is also called a naïve forecast and it must be very simple. In our case, the prediction for each student will be simply the average of the forecasts of all the students with the same instructor. This reference forecast can also be called the do-nothing forecast because it does not differentiate between students in the same class.

Fig. 5 and Fig. 6 show the Mean Absolute Percentage Error of the forecast for the second period generated by the algorithm and the reference forecast. Random Forest forecasts had an average error of $16.4 \%$ meanwhile the reference forecast average error is $17.8 \%$. As expected, the reference forecast average error is higher for each of the 5 instructors when we use the grades as the only input. However, the difference is very slight (especially for Instructor 3, where the difference of $0.1 \%$ is hard to see in Fig. 5).

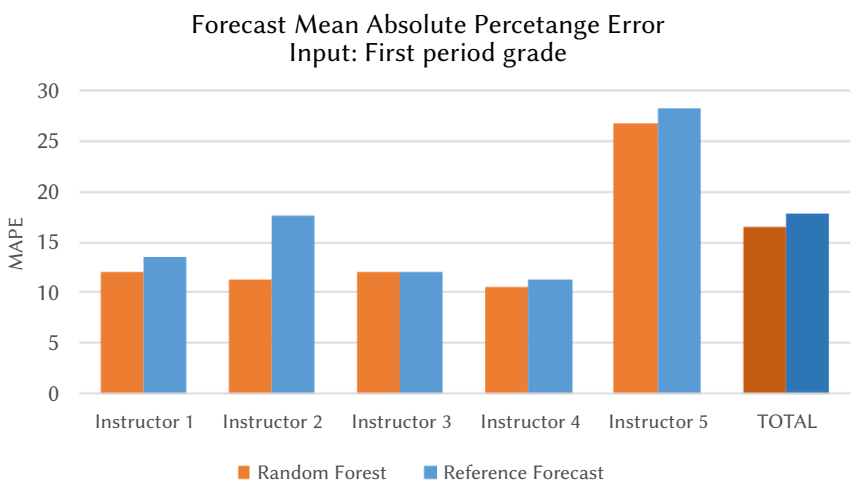

Fig. 5. Validation of the Random Forest forecast compared against a reference forecast. Input: First-period grades.

Surprisingly, when we use the grades and photographs as input (Fig. 6) the difference between both forecasts is less obvious.

Also, second-period grades were harder to predict for instructor 5 class. This may be because this instructor evaluated the first period using some assignments and evaluated the second period with an exam.

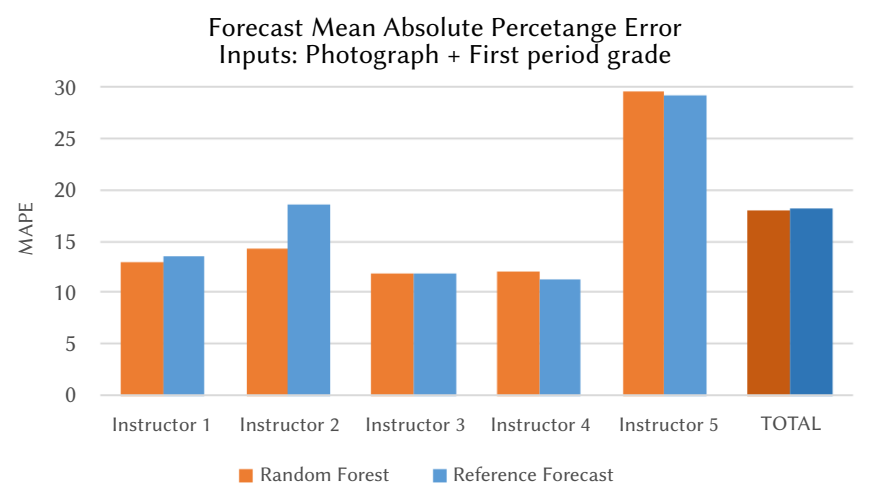

Fig. 6. Validation of the Random Forest forecast compared against a reference forecast. Input: Photograph + First period grades.

Table I presents average results for the first and second evaluation periods of all groups along with the forecast MAD. Note that forecast tends to have a larger MAD in groups when grades have more deviation since it's usually harder to predict values with more dispersion. 
TABle I. Grades From the First and Second Evaluation Periods. The Mean Absolute Deviation of the forecast Produced by the Random FOREST ALGORITHM IS INCLUDED

\begin{tabular}{|l|c|c|c|c|c|c|c|}
\hline & & \multicolumn{3}{|c|}{ Period 1 } & \multicolumn{3}{c|}{ Period 2 } \\
\hline $\begin{array}{l}\text { Instructor 1 } \\
\text { Control }\end{array}$ & 31 & 78.6 & 13.1 & 11.7 & 80.5 & 12.2 & 6.2 \\
\hline $\begin{array}{l}\text { Instructor 1 } \\
\text { Experimental }\end{array}$ & 38 & 77.2 & 12.9 & 11.9 & 80.9 & 12.6 & 11.1 \\
\hline $\begin{array}{l}\text { Instructor 2a } \\
\text { Experimental }\end{array}$ & 17 & 67.8 & 13.9 & 11.8 & 74.1 & 14.4 & 11.3 \\
\hline $\begin{array}{l}\text { Instructor 3 } \\
\text { Control }\end{array}$ & 19 & 93.9 & 5.8 & 5.5 & 95.4 & 5.5 & 11.5 \\
\hline $\begin{array}{l}\text { Instructor 3 } \\
\text { Experimental }\end{array}$ & 18 & 88.6 & 9.3 & 7.6 & 95.4 & 6.2 & 11.9 \\
\hline $\begin{array}{l}\text { Instructor 4 } \\
\text { Control }\end{array}$ & 31 & 95.0 & 8.4 & 10.6 & 90.8 & 13.3 & 7.4 \\
\hline $\begin{array}{l}\text { Instructor 4 } \\
\text { Experimental }\end{array}$ & 28 & 95.5 & 5.8 & 8.3 & 89.4 & 10.0 & 8.1 \\
\hline $\begin{array}{l}\text { Instructor 5 } \\
\text { Control }\end{array}$ & 58 & 73.8 & 15.2 & 12.8 & 82.3 & 19.3 & 19.2 \\
\hline $\begin{array}{l}\text { Instructor 5 } \\
\text { Experimental }\end{array}$ & 28 & 72.3 & 16.8 & 13.3 & 70.6 & 20.9 & 16.4 \\
\hline
\end{tabular}

${ }^{a}$ Instructor 2 only taught one group which was considered an experimental group.

From the interviews, information was obtained regarding the adaptive processes applied by each instructor and in each evaluation period, which lasted five weeks. It is important to clarify that given the number of students per group and that the courses are face-to-face it was complex for teachers to take personalized adaptive measures, so they opted for group measures. Instructors 1 and 2 taught Physics I course, based on the predictions calculated before the first and second periods. They decided to provide more practical exercises give more tutoring time. Instructor 2 also showed the students motivational videos and videos about the subject matter. Instructor 3 was in charge of two honors Physics II groups, that is, students who receive more advanced training than those in a regular course. In the first period of the course, he made available a series of videos that help to complement or review the classes, as well as personal tutoring to the experimental group. In the second period, he added immediate response online tests such as Kahoot, questionnaires for review, and more practice exercises. This instructor is willing to use the Predictive Algorithm as a didactic tool. Instructor 4 had two regular courses of Physics II. This instructor decided that the experimental group would be the group that seemed to be lagging behind. Instructor 4 applied collaborative work and offered tutoring in the first period to the experimental group. In the second period, he changed the collaborative work to in-class discussions as plenary sessions. This instructor does not plan on using the Predictive Algorithm as a didactic tool. Lastly, Instructor 5 also taught two regular Physics II courses. This instructor did not distinguish between the control group and the experimental group, and in the first period offered tutoring and practice exams. In the second period, in addition to providing the same options as in the first evaluation period, he changed the sitting arrangement of the problematic students. Instructor 3 is willing to use the Predictive Algorithm as a didactic tool.

In order to analyze the effectiveness of the adaptive routes applied by each instructor, except for instructor 2 who led only one course, the means of the grades of the second period of both the control group and the experimental group were calculated to determine if the differences were significant. The conclusions are shown in Table II and Fig. 5.
TABle iI. Averages of the Second Evaluation Period for the Control AND EXPERIMENTAL Groups OF The Three Instructors a

\begin{tabular}{|c|c|c|c|}
\hline Instructor & $\begin{array}{l}\text { Average of } \\
\text { the control / } \\
\text { experimental } \\
\text { group }\end{array}$ & $\begin{array}{r}P(T \leq t) \\
\text { one-tail }\end{array}$ & Conclusion \\
\hline 1 & $80.55 / 80.89$ & 0.454 & $\begin{array}{l}\text { There is no statistical } \\
\text { evidence that the average of } \\
\text { both groups corresponds to } \\
\text { different populations. }\end{array}$ \\
\hline 3 & 95.42 / 95.39 & 0.493 & $\begin{array}{l}\text { There is no statistical } \\
\text { evidence that the average of } \\
\text { both groups corresponds to } \\
\text { different populations. }\end{array}$ \\
\hline 4 & 90.84 / 89.43 & 0.325 & $\begin{array}{l}\text { There is no statistical } \\
\text { evidence that the average of } \\
\text { both groups corresponds to } \\
\text { different populations. }\end{array}$ \\
\hline 5 & $82.26 / 70.57$ & 0.006 & $\begin{array}{l}\text { Statistical evidence that the } \\
\text { experimental group obtained } \\
\text { a lower average than the } \\
\text { students in the control group. }\end{array}$ \\
\hline
\end{tabular}

${ }^{a}$ Instructor 2 only taught one group, which was considered an experimental group. Therefore, no comparison control vs experimental is done for instructor 2.

Another result observed pointed out a significant difference between the undergraduate student's mark averages in both groups led by Instructor 5 . The interpretation can be explained by comparing with other instructor's groups. For instance, Instructor 3 had honors groups (advanced students) while Instructor 4 opted that the experimental group would be the group more behind, which implies that he managed to raise the academic level of the group. Regarding Instructor 5, dissonance was noted between the forecast and what happened in the classroom, which arouses suspicion about inconsistencies in the teaching-learning process.

Fig. 5 presents a boxplot for the second-period grades for each group. It shows that the variation among grades given by each instructor is similar in their control and experimental groups (the box height is similar). The groups of Instructor 5 are those that show greater dispersion. The four control groups show atypical observations in the range of low scores. That is, some students obtained atypically low marks concerning the rest of the group. In the experimental groups, only two atypical points are observed in the groups of Instructors 1 and 3. For instructors 4 and 5, although the average of the experimental group is not better than that of the control group, atypically low grades are observed only in the control groups (indicated in Fig. 7 with a circle).

Although it is true that the experimental group was expected to have a better result in statistical terms, it is worth considering external factors that could affect the empirical study: e.g., , class schedule, students' group characteristics, teacher's pedagogical style, etc. Furthermore, it is not possible to know what the performance of the experimental group would have been if the teacher had not taken adaptive actions based on the predictions. On the other hand, an improvement is noted in the groups of instructors 1,2 , and 3 when compared to the qualifications of the first and second periods of the experimental groups (Table I).

We wanted to know the students' opinions about the potential use of the algorithm as a learning tool. At the end of the program, and after learning of what this research was about, students voluntarily answered a questionnaire to let us know their opinion about the scenario when they know their own prediction at the beginning of the semester and what they would do if they were giving their grade forecast. A total of 
45 students submitted their answers. Questionnaires results show that around $80 \%$ of the undergraduates agreed and strongly agreed with the grades they got for assignments, quizzes, and mid-term exams. In other words, their grades aligned with what they expected.
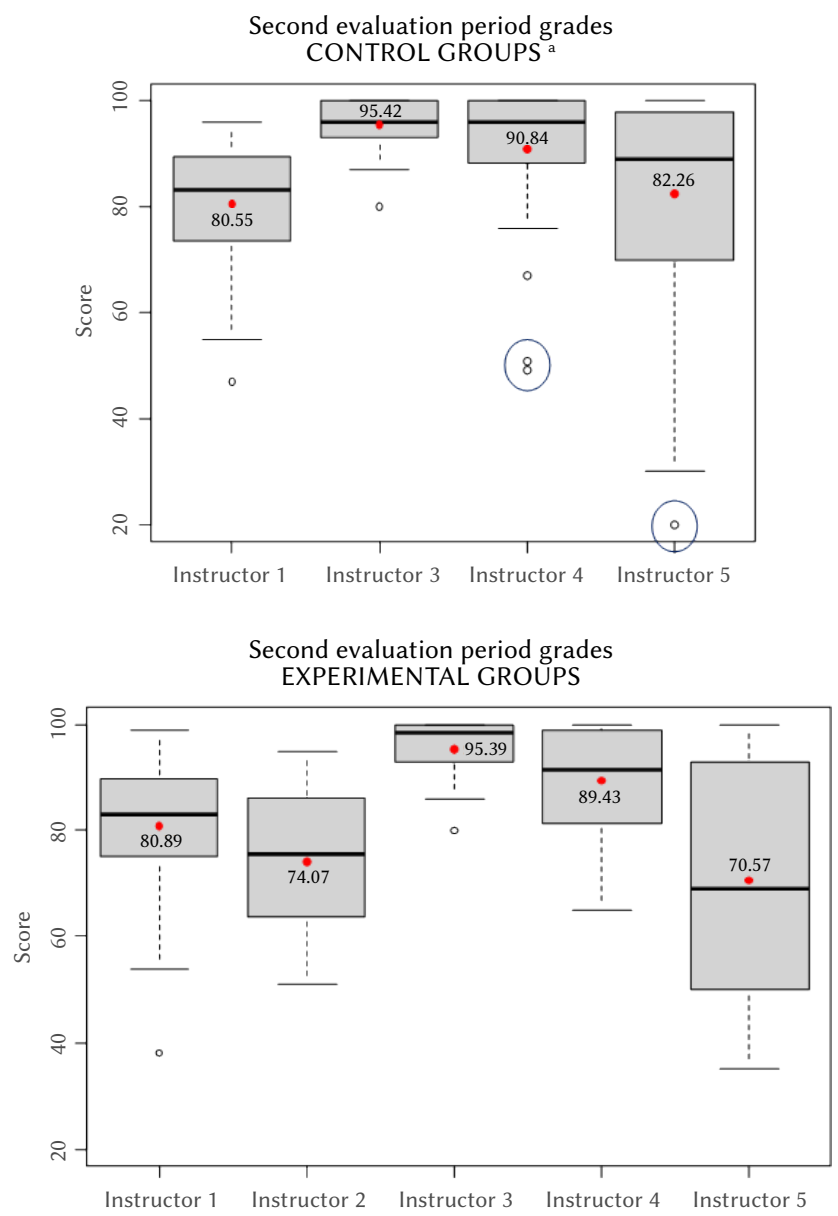

${ }^{a}$ Instructor 2 only taught one group, which was considered experimental group.

Fig. 7. Comparative boxplots. Grades from the second term in both experimental and control groups. The horizontal line inside the boxes represents the median. The little red circle inside the boxes represents the mean and it is labeled with its value.

Also, when they were asked about the chance of using AI to predict their final course exams, they declared that they would like to know the prediction of their academic performance in their courses. See Fig. 8.

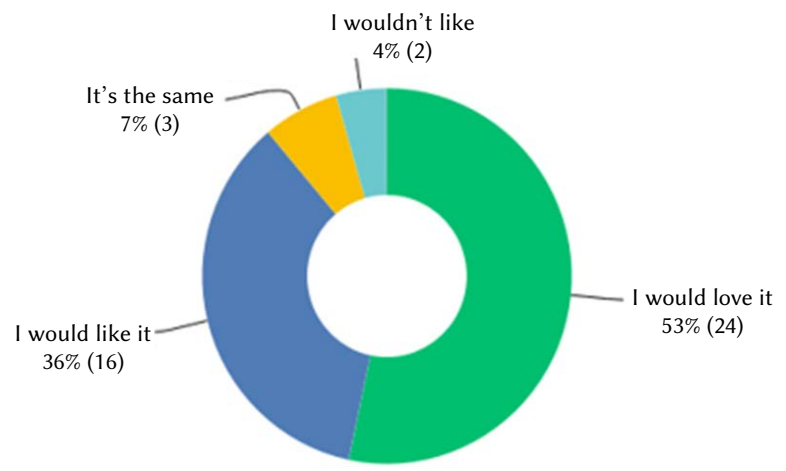

Fig. 8. Undergraduates' opinions about knowing in advance their academic performance prediction by using AI.
In general terms, $53 \%$ of the undergraduates would love to use it and $36 \%$ would like it. Few students (4\%) disagreed with the idea of using this technology to know their performance prediction beforehand.

Another question was about the reason why the undergraduates would like to use the predictive algorithm as part of their academic tools. The answers were grouped into five categories, which are shown in Fig. 9.

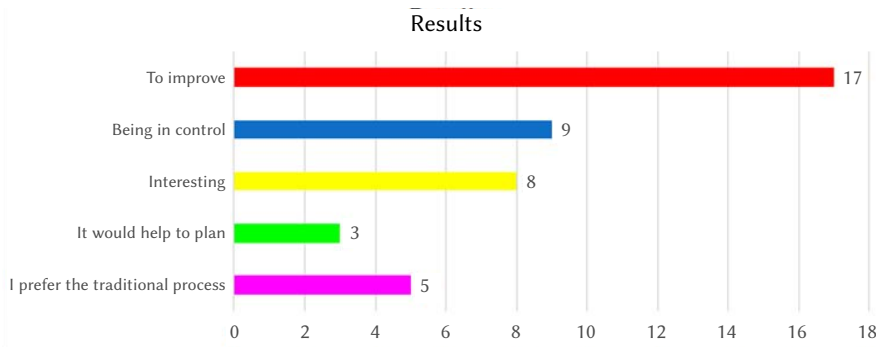

Fig. 9. Undergraduates' opinions about why they would use or not AI to know their forecasted performance.

It is interesting how most students are eager about using predictive algorithms to improve or have greater control of their grades (red color bar). At the same time, other students showed some resistance (purple color bar). Some outstanding opinions of the students were the following:

"It could allow planning and detecting on time what are your weak topics, and you will know what grade you need to stay away from the risk of losing a scholarship" (Student 1).

"It would be interesting, but it could also be a little terrifying" (Student 2).

\section{Discussion}

Predictions become more accurate as of the algorithm trains with a larger amount of data. This is observed in Fig. 1, where the predictions improve as the inputs were made. This matches with what [31] found: the final academic performance of the students could be predicted with greater precision when a third of the semester had already elapsed. So, decision tree-based AI processes can offer more accurate predictive algorithms as they are fed by a greater amount of data of the current course.

Predictive algorithms, based on decision trees, can offer a close approximation to the academic performance that will occur in the classroom in general. This can be seen in Fig. 2 and 4, where the trend between the first and second evaluations is similar. [4] warn in their study that computer-assisted assessments are the best predictor for the detection of low-performing students. This shows that a blend learning format should be adopted in the face-to-face courses using a technological platform. The computerized resource should be selected consensually to homogenize the activities and evaluations.

Although the predictions were not accurate in terms of students' evaluations, they provide an overview of the group's performance. In this sense, the instructor can take group adaptive measures to preventively improve student performance. On the other hand, Adaptive Learning can be complex because the role of the instructor as a mediator is difficult to perform. [32] found in their study that mediators can influence the dynamics of social learning and adaptive learning. Therefore, the use of predictive algorithms can be a didactic tool that favors adaptive learning, offering the possibility of improving teaching practice and student performance.

In this study, both teachers and students agree to use this type of technology as a tool, both to improve teaching practice and to 
improve academic performance, respectively. However, although today's technology can support vast data processing, unlike the 1970s when AI began [19] and [33], there are serious limitations in its use due to the data protection law and ethical aspects [34] that strongly advise not to use facial recognition, for instance, as an input for these algorithms [35].

In this regard, it turned out significant how three of the five predictions were more accurate than using the students' academic records alone. Therefore, colleges and universities could facilitate access to a greater number of data and thereby improve the predictive power of algorithms by covering greater possibilities and reducing the margin of error. In other words, if the algorithm is trained based on students' academic history such as recorded homework, quizzes, and exams, it could be possible to accurately predict that those with a good track record will get good grades. However, it might happen otherwise, as factors such as teacher pedagogical style, students' study habits or personal circumstances may influence the real results. For this reason, feeding the algorithm with a greater amount of data encompasses a greater number of possibilities for future teaching. For example, it will ease teachers' work if they forego initial evaluations of students' aptitude or spot students with difficulties in the course of the teaching program. Or, if the teachers can foresee any group performance trend, then grouping students with low, regular, and high levels could be optimal, as proposed in the work of Villagrá-Arnedo et al. [36].

\section{CONCLUSION}

Based on the research results, the algorithm delivered a forecast of the group performance in general. Therefore, the algorithm can be a valuable resource for the instructor to design and implement adaptative measures. We expect that the forecast will be more precise on final grades.

At the same time, we expect that the individual forecast will be more accurate when the algorithm uses a larger number of variables. In face-to-face courses, there is a legal limitation about the use of personal data, which is an obstacle to getting better data timely.

Given that the forecasts of three out of the five instructors had a smaller margin of error using only the student's academic information, the possibility of making predictions without using facial recognition as the input remains open, eliminating concerns about ethical questions.

\section{ACKNOWLEDGMENT}

The authors would like to acknowledge the financial support by Experimentation and Impact Measurement of Tecnologico de Monterrey, Mexico, in this research. We also thank the instructors who participated in the project: Dr. Santa E. Tejeda Torres, MSc. Jorge A. Lomas Treviño, Dr. Alfonso Serrano Heredia y Dr. Héctor J. Medel Covaxin. The work on this study by Juanjo Mena was performed according to the Russian Government Program of Competitive Growth of Kazan Federal University

\section{REFERENCES}

[1] B. Daniel, "Big data and analytics in higher education: Opportunities and challenges," in British fournal of Educational Technology, vol. 46, no. 5, pp. 904-920, 2015, doi: 10.1111/bjet.12230

[2] F. J. Garcia-Penalvo et al., "Opening learning management systems to personal learning environments," fournal of Universal Computer Science, vol. 17, no. 9, pp. 1222-1240, 2011.

[3] W. Greller and H. Drachsler, "Translating learning into numbers: A generic framework for learning analytics," Educational Technology
Society, vol. 15, no. 3, pp. 42-57, 2012.

[4] D. T. Tempelaar, B. Rienties, and B. Giesbers, "In search for the most informative data for feedback generation: Learning analytics in a datarich context," Computer and Human Behavior, vol. 47, pp. 157-167, 2015, doi: 10.1016/j.chb.2014.05.038

[5] C. Vieira, P. Parsons, and V. Byrd, "Visual learning analytics of educational data: A systematic literature review and research agenda," Computer and Education, vol. 122, no. March, pp. 119-135, 2018, doi: 10.1016/j.compedu.2018.03.018

[6] B. T. M. Wong, "Learning analytics in higher education: an analysis of case studies," Asian Association of Open Universities fournal, vol. 12, no. 1, pp. 21-40, 2017, doi: 10.1108/aaouj-01-2017-0009

[7] A. Martínez-Monés et al., "Achievements and challenges in learning analytics in Spain: The view of SNOLA," RIED. Revista Iberoamericana de Educación a Distancia, vol. 23, no. 2, pp-187-212, 2020. doi: 10.5944/ ried.23.2.26541.

[8] Á. Fidalgo-Blanco, M. L. Sein-Echaluce, F. J. García-Peñalvo and M. Á. Conde-González, "Using Learning Analytics to improve teamwork assessment," Computers in Human Behavior, vol. 47, pp. 149-156, 2015. doi:10.1016/j.chb.2014.11.050.

[9] R. F. Arnove, "Imagining what education can be post-COVID-19," Prospects, vol. 49, no, 1-2, pp. 43-46, 2020. https://doi.org/10.1007/s11125020-09474-1

[10] S. J. Daniel, "Education and the COVID-19 pandemic," Prospects, vol. 49, no, 1-2, pp. 91-96, 2020, doi:10.1007/s11125-020-09464-3

[11] APA [American Psychological Association]. Human behavior in the time of COVID-19: Learning from psychological science, 2020. https://www. psych ologi calsc ience .org/obser ver/human -behav ior-in-thetime-ofcovid -19

[12] M. S. C. Thomas and C. Rogers, "Education, the science of learning, and the COVID-19 crisis," Prospects, vol. 49, no, 1-2, pp. 87-90, 2020, doi:10.1007/s11125-020-09468-z

[13] O. Olmos, M. Hernández, E. Avilés, I. Treviño,. "Optimal Paths for academic performance supported by artificial intelligence," Conference Proceedings of the 6th International Conference on Educational Innovation, CIIE 2018. Monterrey, Mexico, 2018.

[14] G. Chirici et al., "A meta-analysis and review of the literature on the k-Nearest Neighbors technique for forestry applications that use remotely sensed data," Remote Sensing of Environment, Elsevier Inc., vol. 176. pp. 282-294, 01-Apr-2016, doi: 10.1016/j.rse.2016.02.001

[15] V. K. Ayyadevara, "Random Forest" in: Pro Machine Learning Algorithms," Berkeley, CA: Apress, 2018, pp 105-116, doi: 10.1007/978-1-4842-3564-5_5

[16] Y. Koren, "The bellkor solution to the netflix grand prize," Netflix Prize Doc., no. August, pp. 1-10, 2009.

[17] T. Havens, "Netflix. In From Networks to Netflix" Routledge, pp. 321-331, 2019, doi: 10.4324/9781315658643-30

[18] Y. Chen, X. Li, J. Liu, and Z. Ying, "Recommendation System for Adaptive Learning," Applied Psychological Measurement, vol. 42, no. 1, pp. 24-41, 2018, doi: 10.1177/0146621617697959

[19] B. T. Smith, "How adaptive learning really works," Tech \& Learning, vol. 37, no.3, pp. 20-26, 2015.

[20] D. Miliband, "Choice and Voice in Personalised Learning," Pesonalising Education, pp. 9-19, 2006, doi:10.1787/9789264036604-2-en

[21] F. J. Gallego-Durán, R. Molina-Carmona, and F. Llorens-Largo, "Measuring the difficulty of activities for adaptive learning," Universal Access Information Society, vol. 17, no. 2, pp. 335-348, 2018, doi: 10.1007/ s10209-017-0552-x

[22] D. L. López, F. V. Muniesa, and Á. V. Gimeno, "Aprendizaje adaptativo en moodle: tres casos prácticos Adaptive learning in moodle: three practical cases," Education in The Knowledge Society (EKS), vol. 16, pp. 1-12, 2015.

[23] D. Gašević, S. Dawson, and G. Siemens, "Aprendizaje adaptativo en moodle: tres casos prácticos Adaptive learning in moodle: three practical cases," TechTrends, vol. 59, no. 1, 2015.

[24] Y. Chen, X. Li, J. Liu, and Z. Ying, "Recommendation System for Adaptive Learning," Applied Psychological Measurement, vol. 42, no. 1, pp. 24-41, 2018, doi: 10.1177/0146621617697959

[25] M. Belgiu and L. Dragu, "Random forest in remote sensing: A review of applications and future directions," ISPRS Journal of Photogrammetry and Remote Sensing, vol. 114, pp. 24-31, 2016, doi: 10.1016/j. isprsjprs.2016.01.011 
[26] K. Chen, L. Fine, \& B. Huberman, "Predicting the Future". Information Systems Frontiers, vol. 5, no. 1, pp. 47-61, 2003.

[27] M. Castañer, O. Camerino, M. T. Anguera, "Métodos mixtos en la investigación de las ciencias de la actividad física y el deporte". Apuntes Educación Física y Deportes 112, 31-36, 2013.

[28] J. W. Creswell, "A concise introduction to mixed methods research", Thousand Oaks :SAGE, 2015.

[29] S. Olmos, J. Mena, E. Torrecilla \& A. Iglesias.Olmos. "Improving graduate students learning through the use of Moodle," Educational Research and Reviews, vol. 10, no. 5, pp. 604-614, 2015.

[30] M. Gilliland, "The Business Forecasting Deal," New Jersey, USA: John Wiley and sons, 2010.

[31] O. H. T. Lu, A. Y. Q. Huang, J.C.H. Huang, A. J. Q., Lin, H. Ogata, S. J. H. Yang, "Applying learning analytics for the early prediction of students' academic performance in blended learning," Educational Technology and Society, vol. 21, no. 2, pp. 220-232, 2018.doi: 10.2307/26388400

[32] B. Szijarto and J. B. Cousins, "Making Space for Adaptive Learning," American fournal of Evaliation, pp. 1-17, 2018, doi: $10.1177 / 1098214018781506$

[33] EduTrends, "Aprendizaje y evaluación adaptativos (adaptive learning and evaluation)," Observatorio de Innovación Educativa del Tecnológico de Monterrey, no. Julio, 2014.

[34] F. J. García-Peñalvo, "Learning Analytics as a Breakthrough in Educational Improvement," in Radical Solutions and Learning Analytics: Personalised Learning and Teaching Through Big Data, D. Burgos, Ed. Lecture Notes in Educational Technology, pp. 1-15, Singapore: Springer Singapore, 2020. doi: 10.1007/978-981-15-4526-9_1.

[35] S. Agarwal and D. P. Mukherjee, "Facial expression recognition through adaptive learning of local motion descriptor," Multimedia Tools and Applications, vol. 76, no. 1, pp. 1073-1099, 2017, doi: 10.1007/s11042-0153103-6

[36] C. J. Villagrá-Arnedo, F. J. Gallego-Durán, F. Llorens-Largo, R. SatorreCuerda, P. Compañ-Rosique and R. Molina-Carmona, "Time-Dependent Performance Prediction System for Early Insight in Learning Trends," International fournal of Interactive Multimedia and Artificial Intelligence, vol. 6, no. 2, pp. 112-124, 2020. doi: 10.9781/ijimai.2020.05.006.

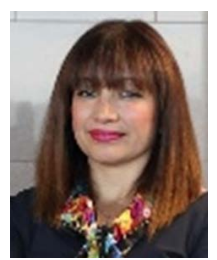

\section{Elvira G. Rincon-Flores}

Elvira G. Rincon-Flores holds a PhD in Education Sciences from the University of Salamanca, Cum Laude thesis. She is a research professor and experimental and impact measurement scientist of the Institute for the Future of Education at the Tecnologico de Monterrey. Currently, she belongs to the National System of Researchers (SNI), to the research groups: GRIAL and GIIE, the University of Salamanca, and Tecnológico de Monterrey, respectively. She has been the leader of two research projects: Predictive Algorithm based on Artificial Intelligence for learning, and Educational Spaces of the Tec 21 model. It also collaborates with the University of Lima in the development of a dynamic platform for Gamification. Her lines of research are: Educational innovation, educational technology, and evaluation of didactic strategies for learning.

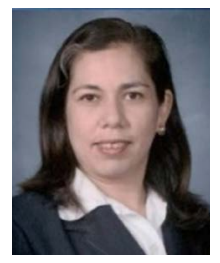

Eunice López-Camacho

Eunice López-Camacho holds a $\mathrm{PhD}$ in Information Technology and Communications (2012) from the Tecnologico de Monterrey, with a dissertation about producing hyper-heuristics for solving the two-dimensional irregular bin packing problem. Eunice's academic experience is mostly about teaching Probability, Statistics, and Algorithm Analysis. She has a multidisciplinary range of research interests, including statistical applications in education and manufacturing industry, optimization, hyper-heuristics, and evolutionary computation. Her public profile is available at Research Gate (https://www. researchgate.net/profile/Eunice_Lopez5).

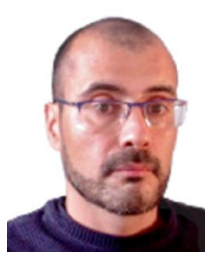

Juanjo Mena

Juanjo Mena $(\mathrm{PhD})$ is Associate Professor at the department of Education in the University of Salamanca, Spain. He is the treasurer of the ISATT and research collaborator in Kazan Federal University, Russia. His work in this study was performed according to the Russian Government Program of Competitive Growth of Kazan Federal University. His research interests: mentoring, practicum, Teacher Education and ICT.

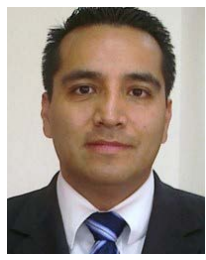

\section{Omar Olmos}

Omar Olmos is a full-time professor at the Tecnológico de Monterrey. Holds a PhD in nonlinear Physics, actually, he is an academic director of the North Region science department. He has oriented his academic work to the development of effective educational technology for science learning, as well as new models for the evaluation and development of progressive competencies in science courses. He has given workshops and conferences at national and international universities in Mexico, the United States, Spain, Peru, Colombia, and Chile. $\mathrm{He}$ is a consultant on issues of educational innovation, sustainable business development, change management and technological transformation models supported by technology. He has developed and supported Artificial Intelligence models for both academic forecasting and data patterns in different domines. 